\title{
Training U.S. Workers for the Next Generation of Technology
}

The United States's technological prowess demonstrates great ingenuity and inventiveness. That is a major reason why, despite our recent slowdown and the aftershocks of the September 11th attacks, we still have a strong and vibrant economy.

But our long-term competitive standing and economic security could well be at risk if we do not address a troubling trend in our workforce - the mismatch between the demand and supply of workers with science and engineering training.

Recent studies show that the number of jobs requiring significant technical skills is projected to grow by more than $50 \%$ in the United States over the next decade. But outside of the life sciences, the number of degrees awarded in science and engineering has been flat or declining.

The declining number of degrees has helped fuel a well-chronicled shortage of qualified New Economy workers. We have tried to temporarily plug this humancapital hole with a stopgap of non-U.S. workers. But there is a broad consensus among high-tech leaders and policymakers that it would be a serious mistake to prolong this dependence.

We now know that technological innovation is the major driver of economic growth, not to mention a critical factor in our military superiority. And it is widely understood that we cannot expand our economy in the future if we do not take steps now to expand our domestic pool of brainpower-the next generation of people who will incubate and implement the next generation of ideas.

Now, most answers to serious economic challenges flow from the private sector, which is where growth ultimately occurs. But there are ways that the federal government can help, particularly in the area of educating and training our workforce. The federal government can provide leadership, focus, and not least of all resourcesand that is the purpose of the Technology Talent Act of 2001.

Recent studies show that the number of jobs requiring significant technical skills is projected to grow by more than $50 \% \ldots$

This legislation-which I recently introduced with Senators Barbara Mikulski, D-Md.; Christopher Bond, R-Mo.; Bill Frist, R-Tenn.; and Pete Domenici, R-N.M.aims to fix a critical link in this "tech talent" gap: undergraduate education in science, mathematics, engineering, and technology.

This bill (S. 1549) would create a new competitive grant program within the National Science Foundation that would encourage institutions of higher learningfrom universities to community collegesto increase the number of graduates in these disciplines.

This is not another scholarship program, but a targeted, results-driven initiative aimed at those in a position to effect significant change, namely, institutions of higher education. The bill asks them to formulate effective ideas for reversing the decline in the number of graduates, and we will provide the dollars to implement those ideas.

For example, institutions could propose to add or strengthen the interdisciplinary components of undergraduate science education. Or, recognizing that increasing the diversity of the workforce is one key to expanding this workforce, institutions could establish or expand existing targeted support programs for women and minorities. Currently, women and minorities make up $54 \%$ of our total workforce, but only $22 \%$ of scientists and engineers.

Or institutions could partner with local engineering companies to provide summer industry internships, thereby exposing students to interesting opportunities beyond the classroom and helping them to realize the benefits of a technical degree.

Our plan and the corresponding House bill-which is sponsored by House Science Chair Sherwood Boehlert, R-N.Y., and Representative John Larson, D-Conn.authorizes the program at $\$ 25$ million for fiscal year 2002. But our bipartisan coalition hopes the level will rise over the next several years to approximately $\$ 200$ million annually, based upon pilot program results. With that kind of seed money, we are optimistic that thousands of promising new scientists and engineers will soon bloom.

I hope that materials researchers, along with colleagues across the spectrum of science and engineering disciplines, will begin thinking about how best to reverse the decline in the number of students studying and receiving degrees in science, engineering, mathematics, and technology. And I hope that the Technology Talent Act of 2001 will serve to encourage and support the most promising ideas and new programs that you will propose, so that together we can begin to address this national dilemma.

SEN. JOSEPH I. LIEBERMAN

Senator Joseph I. Lieberman, D-Conn., co-sponsored the Technology Talent Act of 2001 (S. 1549), which was introduced to the U.S. Senate in October of last year.

\section{MRS special delivery}

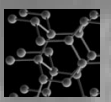

Let MRS bring public policy information to you: Sign up today!

MRS Public Affairs Alert

mrs-publicaffairs-subscribe@mrs.org

Receive concise summaries of current public policy issues affecting materials science

and engineering and learn what actions you can take to make a difference.

www.mrs.org...the Materials Gateway 